\title{
Rapidly enlarging scalp nodules in a 20-month-old child
}

\author{
Feras M. Ghazawi MD PhD, Kevin Cheung MD, Geneviève Gavigan MD
}

- Cite as: CMAJ 2020 September 14;192:E1066. doi: 10.1503/cmaj.200314

A 20-month-old girl was referred with multiple rapidly growing, painless, subcutaneous scalp nodules (Figure 1). She was otherwise well, with no history of trauma or headaches. On examination, the child appeared well. On the scalp, there were several prominent spherical, mobile and rubbery nodules with no tenderness or fluctuance. There was no overlying skin change. A history of an upper respiratory tract infection preceded the appearance of the nodules. Magnetic resonance imaging (MRI) showed 5 nonvascular and nonspecific subcutaneous lesions with no perilesional edema and no intracranial extension. Excisional biopsies of 4 lesions showed a palisaded granulomatous inflammatory process with a peripheral rim of necrobiosis, compatible with benign subcutaneous granuloma annulare, a subtype of granuloma annulare that primarily affects girls younger than 6 years. ${ }^{1}$ Granuloma annulare is usually self limited, but topical or intralesional steroids can be used for symptomatic or persistent lesions.

The differential diagnosis of subcutaneous scalp nodules in babies and toddlers is broad and includes benign, infectious and malignant entities. ${ }^{2}$ Multiple rapidly growing nodules may be alarming, but benign causes include subcutaneous granuloma annulare, deep infantile hemangioma and juvenile xanthogranuloma (deep subtype). Less commonly, infections such as deep fungal and nontuberculous mycobacterial infections may present as multiple nodules but are often associated with fever, secondary skin findings and satellite lesions. Finally, it is important to rule out diagnoses that carry high morbidity or mortality. Several malignancies may present this way, such as Langerhans cell histiocytosis, rhabdomyosarcoma, lymphoma, leukemia and metastatic neuroblastoma.

Evaluation of a baby or toddler presenting with a subcutaneous scalp nodule includes a thorough history, physical examination and investigations (e.g., imaging and histopathology) as necessary. The progression of the nodule can aid in the diagnosis; for example, whether the nodule was congenital or has grown. Constitutional symptoms may suggest malignant disease. The number, location (e.g., midline) and characteristics of the nodules on physical examination should also be taken into consideration.

Imaging studies, including ultrasonography, computed tomography and MRI, may be helpful by identifying specific features of these lesions (e.g., connecting tracts, calcification and abnormal vasculature). ${ }^{3}$ Our patient's lesions partially resolved within a few months; no topical or interlesional steroids were used.

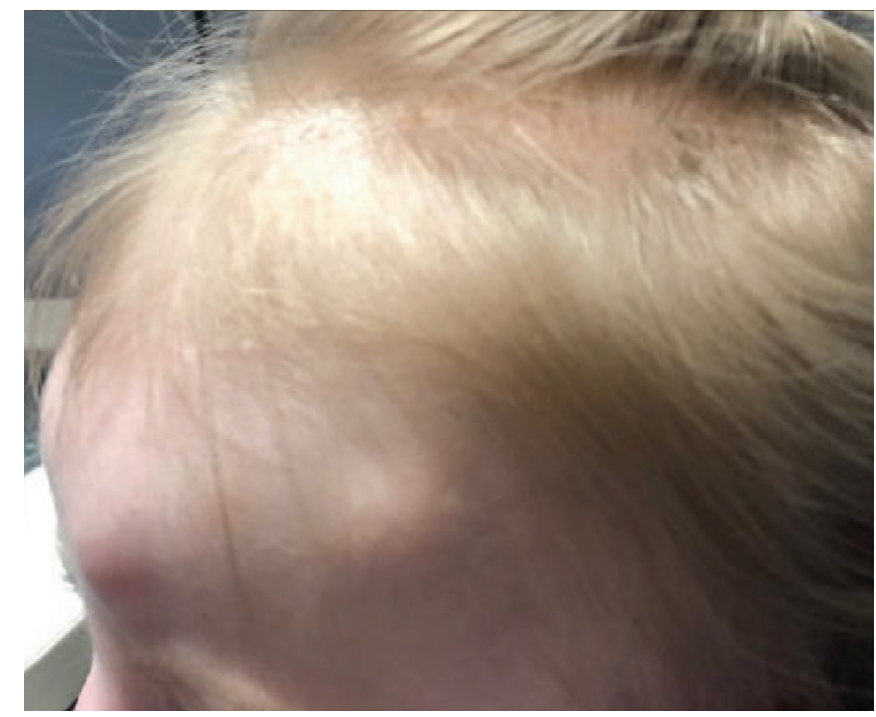

Figure 1: Scalp of a 20-month-old girl showing multiple subcutaneous nodules with no overlying skin changes.

\section{References}

1. Thomas C, Morley K, Schmidt B, et al. Subcutaneous granuloma annulare involving the scalp. Pediatr Dermatol 2018;35:e72-3.

2. Suresh R, Sugarman J. Rapidly growing cutaneous nodules on the scalp. Cutis 2019;103:E16-8.

3. Rodríguez Bandera AI, Sebaratnam DF, Feito Rodríguez M, et al. Cutaneous ultrasound and its utility in pediatric dermatology. Part I: Lumps, bumps, and inflammatory conditions. Pediatr Dermatol 2020;37:29-39.

Competing interests: Geneviève Gavigan reports receiving honoraria from Valent, Novartis, Sanofi Genzyme, AbbVie, Lilly and L'Oreal, outside the current work. No other competing interests were declared.

This article has been peer reviewed.

The authors have obtained parental consent.

Affiliations: Division of Dermatology (Ghazawi, Gavigan), University of Ottawa; Division of Plastic Surgery (Cheung), Children's Hospital of Eastern Ontario, Ottawa, Ont.

Correspondence to: Geneviève Gavigan, ggavigan@cheo.on.ca 